\title{
Socio-Economic and Psychological Problems of the Senior Citizens of Pakistan
}

\author{
Amir Alam ${ }^{1}$ \\ Shaheed Benazir Bhutto University \\ Muhammad Ibrar ${ }^{2}$ and Parveen Khan ${ }^{3}$ \\ University of Peshawar
}

All human beings are susceptible to numerous problems in life however the elderly population is much more vulnerable to such issues. The number of elderly population is increasing particularly in the developing countries. In 2050, it is estimated that the world will have more aged people than the children less than 15 years (Muhammad, 2013). Although elderly have better contributed in the development during their productive time, however, their contribution has not been acknowledged. They are not properly cared by their family members rather they are abused mentally and physically. They have weak economic status due to their weak physical and mental health. They are not allowed to be involved in decision making. These deprivations and deplorable condition have led them to be dependent on others. In Pakistan till now, no social policy has been devised which could have been influential in the solution of the elderly problem. This literature based study highlights the problems of the senior citizens of Pakistan.

Keywords: elderly population, mental health, pension and health care

Nowadays aging is less considered a natural phenomenon however it is true that aging is a natural biological change and is a universal phenomenon (Pesic, 2007). It is a physiological development like other stages of biological life.

${ }^{1}$ Lecturer, Department of Social Work, Shaheed Benazir Bhutto University amiralamsw@yahoo.com

${ }^{2}$ Assistant Professor, Department of Social Work, University of Peshawar

${ }^{3}$ Assistant Professor, Institute of Education \& Research, University of Peshawar, Pakistan 
Throughout life, human being passes through various stages i.e. babyhood, childhood, adulthood, middle age and old age. However, baby hood, childhood and old age require special care. The old age does not have due care same as the baby hood and childhood. The number of old age people has increased ever before (Chohan, 2007).

However, the elderly population is increasing particularly in the developing countries of the world. According to the 2012 report of the United Nations Population Fund (UNPF), in 2000, there were more aged (above 60 years and above) worldwide than the children under 5 years. Similarly it is estimated that in 2050, the world will have more aged people than the children less than 15 years. The main reason behind this growing rate of elderly population is the decline in mortality rate due to the advancements made in the fields of medicine and nutrition whereby aging, to some extent, can be prevented or delayed. This improved life expectancy has ultimately increased the number of older people and can live long as a result of better nourishment, hygiene and health care (Muhammad, 2013).

Senior citizens have better contributed to the development of the society during their productive time. Like children and women, older people have no comprehensive and potential international conventions that could address their rights (Dildar, Saeed \& Sharjeela, 2012). However, keeping in account the unforgettable services rendered by the elderly in different capacity, the United Nations declared 5th October to be observed as an International Day of the older persons across the globe (Muhammad, Jan, Shah \& Ahmad, 2009). According to the United Nations estimates, the current population of Pakistan is 191,326,717 and this is equivalent to $2.57 \%$ of the total world's population (Worldometers). Among these we have nearly 18 millions of elderly aged 60 and above (Mansoor, 2016).

State is responsible for the provision of basic health facilities i.e. food, shelter, health but unfortunately this is not practical in Pakistan due to the incapability of the state. The absence of state and societal support for the whole population particularly for the elderly population has been traditionally compensated by the presence of a strong and unconditional family support. However, the traditional joint family system is changing to nuclear family and due to this breakdown in the structure of the family the health of the elderly is deteriorated since in nuclear family elderly parents have little or even no authority and their care and support is neglected.

PESHAWAR JOURNAL OF PSYCHOLOGY AND BEHAVIORAL SCIENCES,2016,VOL.2, NO. 2, 249-261 
Most of the older adults have problem of maltreatment which includes; physical, sexual, financial and material abuse, psychological, emotional,; abandonment; neglect; and serious loss of dignity and selfrespect however due to culture values and other reasons they scared or are unable to report it and ultimately this maltreatment can lead to physical injuries and also sometimes long-lasting psychological consequences i.e. depression and anxiety (Yasamy, Dua, Harper \&Saxena 2013). Many nongovernmental organizations e.g. Ladies Fellowship, Pakistan Senior Citizens Association (Karachi based), Pakistan Association of Gerontology and Association for the Welfare of the Retired Persons (Islamabad based) have been established for the welfare of the elderly population however these organizations could not succeeded in their cause since these organizations were either had financial limitations or their efforts did not improve the lot of the elderly population (Khalid, 2001).

\section{Objectives of the Study}

1. This descriptive nature of study has been carried out with the objectives to.

2. Know about the potential problems faced by the elderly population of Pakistan.

3. Identify the contributing factors which negatively reinforce the problems of the senior citizens.

\section{Economic Problems}

Poverty and economic constraints are especially troublesome of the elderly as they have very low possibilities to recover from the drop in income (Cherchye, Rock \& Vermeulem, 2008). Though elder economic abuse was first identified by the developed countries by carried out research studies however, the developing countries have also realized that economic abuse of the elderly is a universal phenomenon. In Pakistan old age is considered as a mark of esteem, wisdom and piety. This is due to the strong ties that exist in the joint family system nurtured by religious values, dignifying the status of elderly segment of society. Elderly have been seen and observed to have invested on their children for the sack of their bright future. However, due to the impact of the western media on our youth it has been noticed that these children have left their parents on the mercy of God as these youngsters like to live separately and do not 
prefer to be with their parents due to their privacy. As a result, this group of elderly is more likely to suffer from poverty.

In Pakistan, particularly in the rural areas, older people have been replaced as head of the households in the name of affection and cultural norms which has deprived them from financial autonomy. Such affection and overprotection have lead the older persons isolated, demoralized and depressed. Moreover, in many families, as a custom in Chitral (a District of Khyber Pakhtunkhwa), widows are not allowed to remarry as the property of that widow will remain with their heirs. During their old age such widows face lots of economic hurdles. Similarly over-mortality of the male/husbands of women leads to an increase in the rate of single women in the older age groups and as a result these single women need financial support (Salahuddin and Jalbani, 2006). In such a situation these women due to their financial constraints and being vulnerable face tremendous financial hurdles. Ultimately, such older women have also been seen to indulge themselves in the curse of beggary. Studies have shown that due to the poverty in old age women have started prostitution as a profession and an organized crime. Many of the elderly are left as single because of the death of their spouse. The incidence of the remarriage, in many regions, of a widowed or divorce is lower among women than men. Owing to this cultural taboos large proportion of widowed or divorced women remain economically dependent. Furthermore the loss of a spouse has also a negative psychological impact on the remaining partner.

Research reveals that 33 percent of Pakistani population is living below poverty line and this increase in the level of poverty has undoubtedly affected the lives of elderly population (Ali and Kiani, 2003). Poverty has enlarged their financial constraints and leads to psychological issues like depression. In case of employment they are fired by the employers due to their less ability to participate in the socio-economic activities effectively.

Pension system is designed in order to provide the elderly or individuals who loss earning capacity during old age, death of wage earner in the family and incident of disability. Unlike the senior citizens in many developed states around the world, elderly in Pakistan don not receive pension rather government pension plans are available for those who are employed in government sector or working in organized sector only. However despite of the pension, most of the senior citizens are unable to find alternative source of income as pension can't meet their 
subsistence requirements and thus they become dependent on others for financial support (Sabzwari and Azhar, 2010). In many industries in Pakistan, elderly are working on contract basis and they are not entitled for pension (Arif and Ahmed, 2010). Though they are entitled for the same on non-contributory basis however, they are even not considered fit for contributory system and thus after their retirement they are deprived of pension.

\section{Low Status of the Elderly}

Low status of the elderly is considered to be the cause of aging. In past, elderly had enjoyed a very influential and high status due to their strong financial status and cultural norms but now the status of the elderly has been declined due to the changing trends of life. The elderly have no strong hold in house hold economy as children learned through formal institutions and no longer dependents upon their parents for their livelihood since they are capable of making a living by adoption a profession that is independent of their parents. Similarly the society considered the elderly to be unskilled and that their work and efforts are no more contributory. Their skills and contributions are viewed as outmoded even before they retire (Salahuddin and Jalbani, n.d). Freedom of taking decision determines the independence and autonomous status of a person. Today's elderly have less say in the decision making and most of the decisions are taken by their children while decisions by mutual consent are taken rarely (Ali and Kiani, 2003).

\section{Health Problems}

Every culture and every environment produces its own type of elderly population. An educated older adult has more chances to preserve his mental intellectual balance when compared to his uneducated peer in whom decline of health physical and spiritual vitality are more likely to occur

Physical environment, marital status, smoking, obesity are the variables that also determine the longevity in a particular society. Similarly the quality of food is potential determinant in longevity. Research indicates that in Pakistan, most of the elderly don't eat meat and lack fresh fruits and vegetable (Pesic, n.d). We have no food stamps programs/ schemes for the poor and deserving elderly which is considered to be the state responsibility.

PESHAWAR JOURNAL OF PSYCHOLOGY AND BEHAVIORAL SCIENCES, 2016,VOL.2,NO. 2, 249-261 
Similarly health care facilities are based on a weak infrastructure due to inadequate allocation of budget in health sector. Elderly need long term institutionalized services however the residential and rehabilitation facilities for the older population have not been satisfactory (Cassum, 2014). We have very few Non-Governmental Organizations (NGOs) serving elderly population. Health care of the elderly is not regarded as a distinct specialty rather they are treated by the general practitioner or other specialist. Such care is often fragmented and lack comprehensive care and treatment. There is lack of inpatient rehabilitation centre for patient with strokes, fractures and the outpatient therapy services are widely available but its use is suboptimal (Sabzwari and Azhar, 2010).

Majority of the elderly population has one or more chronic illness like heart disease, hypertension and diabetes etc. As a result of these chronic diseases, this class is vulnerable to various disabilities, nutritional challenges, depression and loss of independent functioning. The number of old age homes is in the country is equal to nothing as a few old age homes are inadequate for huge elderly population. Though volunteers and other generous people run some old age homes where most dependent and vulnerable elderly are provided with free and valuable services. However this is not enough to absorb the influx of elderly suffering from health and accommodation problems (Sabzwari and Azhar, 2010).

\section{Psychological Problems}

Social support and family interaction can increase and boost the dignity of the older adults and such support has a protective role in the maintenance of mental health. Most of the family members in Pakistan have been noticed while threaten and beating their parents. Majority of these family members have found to be the sons. In psychological abuse of the elderly, the most common is the verbal abuse i.e. passing harsh words and humiliation etc and calling names are very common and such behavior of the youngsters affecting both elderly male and female. The youngsters also quarrel with their parents and give arguments every time (Dildar et al, 2012). Mothers, comparatively have been the victim of psychological abuse due to their physical and psychological weaknesses. Similarly, since the fathers have some control over their children therefore the children can't dare to abuse the fathers easily. However, this is not universal as research indicates that fathers have reported their sons to use beat them, calling them names, passing harsh words and even treat them brutally.

PESHAWAR JOURNAL OF PSYCHOLOGY AND BEHAVIORAL SCIENCES,2016,VOL.2, NO. 2, 249-261 
Elderly have got a variety of mental health problems such as anxiety and depression. Such mental health problems have negative impact on the ability to function and result in high rate of disability. These mental health problems are basically the result of the psychological problems and $40 \%$ of psychological problems are the cause of social problems. The death of a spouse has a negative psychological impact on the survived partner. Most of the family members do not allow the elderly to have a second marriage. While it is possible by getting married to have a life partner which has positive impacts on individual life and is source of psychological satisfaction.

In the present Pakistani society, elderly have lot of mental health problems which need to be addressed. However, studies show that almost two-third older adults having mental disorder do not receive the required mental health services.

Depression of elderly is a major public health and a rapid growing problem in both the developing countries and developed world. According to Ganatra, Zafar, Qidwai, \& Rozi, 2008, Pakistan has $22.9 \%$ of elderly population facing depression (Cassum, 2014). According to a cross sectional study, carried out in Rawalpindi and Islamabad, the prevalence of depression among unemployed elderly individuals is double than the employed (Cassum, 2014). Similarly according to the World health Organization (WHO), in 2020, depression will remain a major cause of disability and second only to the cardiovascular disease (APA, n.d). Magnitude of depression among elderly in Pakistan is too much greater than what has been reported. Even in the Unites State, the rate of depression is low than Pakistan i.e. $40 \%$ in United States and $66 \%$ in Pakistan (Cassum, 2014). The problem is acute particularly in the rural and vulnerable groups i.e. poor and some ethnic and racial groups (APA, n.d). Among the mental health problems depression is the major one.

\section{Neglect and Isolation}

Due to globalization and modern technology, the values of families' get together; setting in common hujra (community Hujra) and informal relationship with family members have been decreased. Owing to this, the elderly population has been neglected by the family members. Because of this ignorance of the family members the elderly feel themselves to be isolated from the society. They are not facilitated by their sons and daughters to have meeting or visits and communication with their friends and relatives. Such behavior of the family members 
creates in them a sense of helplessness and hopelessness. Research indicates that among the elderly, women have been noticed to have feeling of loneliness and isolation because of maltreatment of the family members (Dildar et al, 2012). A study conducted by the Senior Citizen Welfare Trust indicates that 98 per cent of the elderly population prefers to stay with their families rather than to be admitted to old age house or somewhere else (Daily Dawn, 2016).

\section{Role in Decision Making}

Most of the elderly, living in nuclear families, takes most of the decision by themselves regarding household. However, in joint and extended family set up elderly do not have an influential role which they had in the past. Almost all the important decisions are taken by the youngsters. The youngsters considered the elders to be conservative and they regard that the elderly are reluctant to social change (Ali and Kiani, 2003). Being vulnerable, the elderly do not reject the decision taken by their youngsters as the elderly may face negative repercussion of this opposition. Research studies indicate that the elderly have countless concerns over their sons regarding the important decisions. Elderly have not even been informed by their sons while they get married. Misperception about modernization and liberalism has changed the social fabric of the society and the direct victims of these concepts have been the present young generation. Youth have been found to have established a neo-local residence after getting married.

According to Ali and Kiani (2003), only $61 \%$ of elderly population does not take part in decision making rather they have no say in decision making process. Similarly, more female then male have not been involved in decision making regarding household (Ali and Kiani, 2003). In Pakistan, particularly in Pakhtun society, elderly women have not been influential in decision making process rather it is the male who decides most of the important household decisions. Furthermore, the decision making power by the elderly of the urban area is more as 37 percent as against 26 percent for the elderly of the rural area.

\section{Physical Abuse}

Elderly population has also been the victim of physical abuse. Dildar (2012); study concluded that $60 \%$ of the elderly were physical abused by their sons. Physical abuse includes slapping, injury and hitting. 
Research indicates that family members, particularly sons have used beating their fathers and mothers. Sons not only beat them rather they have left their elderly alone or on the mercy of others. Elderly have either left alone or many have also been observed who were living alone due to the vulnerability of various kinds of abuses at home.

Despite of the strong economic status of the family members, the elderly have been compelled for employment. Employment of the elderly makes them physically weak and this weakness ultimately leads them to be vulnerable to other social and psychological problems. Elderly have even been forced by their family members to beg for survival of their life. This is a big dilemma for the elderly to be beggar even in the presence of their young sons and family members. Owing to unfair and irresponsible behavior of the family members elderly have also seen to depend on their neighbors for their subsistence requirements.

\section{Transport Problem}

In America, one half of 65 years or older have access to public transportation to meet their daily needs (Alexandra, 2008). One of the problems facing by Pakistani senior citizens is the transport problem. Since majority of the Pakistani are living in rural areas therefore elderly residents of rural areas have less access to necessary services and rely more heavily on private transportation (Ibid). There is either no transport facility for the elderly population or they are too poor to pay. The public system also offers no relief to our elderly and there is no subsidized transportation system present for senior citizens in Pakistan. This situation has restricted the movement of the senior citizens to their place of living. Owing to the non-availability of transport facility they are unable to get the medical facilities in time of emergency as their physical handicaps do not allow them to reach the place of facility or come back to home (Salahuddin \& Jalbani, 2006). Though in some cities of the country the local governments have notified half fair for the elderly however the same could not been implemented.

\section{Sports and Recreational Facilities}

It is stated that healthy body has healthy mind. In order to have healthy body and healthy mind one need happy and smooth life style. Besides this, sports and recreation is also a pre requisite for healthy life. Throughout the world every year October 5th is celebrated as the 
International Senior Citizen day by conducting seminars, meetings and walks to show sympathy and respect for the elderly population (Muhammad, Jan, Shah \& Ahmad, 2009). However, this is not ample rather we must take practical steps in order to achieve long lasting benefits. In developed countries elderly have been the attention of policy makers and numerous recreational facilities have been provided to the elderly population. But in Pakistan, unluckily the elderly don't have any such facilities. Sports and recreation has been an effective tool in the fight against mental health problems since sports and recreation keep one busy. Like children and youngsters, elderly also deserve to have sports and recreation.

\section{Conclusion}

Aging is biological and universal phenomena. However child hood and elderly population require special need. The main reason for the increasing elderly population is the advancement in the field of medicine and nutrition whereby aging, to some extent, can be prevented or delayed. This advancement has ultimately led to the increase of elderly population and today the world has more population than the children less than five years. Though in Pakistan, we are living in family system, however the family system is changing from joint and extended to nuclear family system. Owing to change in the family structure, elderly have got numerous problems. They have no hold in house hold economy since they are no more able to earn for themselves. This economic dependency has weakened their status in the society. They have little say and influence in decision making as most of the decisions are taken by their children. Families have been ignorant and don't give attention to their elders. Son and daughters even don't facilitate their parents to have meeting or visits and communications with their relatives and friends. Health care of the elderly is a distinct specialty while our elderly population is treated by the general practitioners which have led the elderly to be prone to other health problems. Elderly have been noticed while threaten and beating by their sons. Verbal abuse i.e. passing harsh words and humiliation etc and calling names are very common. Such maltreatment of the youngsters has made their elders to be the patients of depression and other mental health issues. There is no public transport scheme for this vulnerable group. Recreational facilities for the elderly has not been realized and acknowledged.

PESHAWAR JOURNAL OF PSYCHOLOGY AND BEHAVIORAL SCIENCES,2016,VOL.2, NO. 2, 249-261 


\section{Suggestions}

In order to have healthy and sound elderly population, the following suggestions are recommended.

1. The joint and extended family system should be restored as these have been influential against many giants and social issues, support of the family members in old age.

2. Our major consideration should be the advocacy of the cause of elderly population by promoting respect for the dignity, equality and violation free society.

3. The government should provide the elderly with better health care facilities in their door step in order to have healthy and happy older population.

4. Social and emotional supports are not less important than physical support in the life of an elderly. A holistic approach is, therefore, required to meet the needs of the elderly population.

5. Owing to globalization and modernization our youth have ignored and rejected their elders. It is therefore considered to be incredible to instill into young a sense of respect and caring for the older people.

6. Older people can be supported through rehabilitation to remain independent and carry out basic tasks so that their functional health is maintained.

7. Those elderly who do not have to be admitted to hospital can be cared for at home by their families. Subsidized medicines and home care may be arranged.

8. Psychotherapy and mental health services for elderly shall also be provided on priority bases.

9. The religious scholars should stress on the rights of the elderly population on different forums.

\section{References}

Ali M. Syed and Kiani F. Muhammad (2003). Ageing and Poverty in Pakistan. Islamabad: Pakistan Institute of Development Economics. Mimap Technical Paper Series No. 18

American Psychological Association (n.d). Psychology and Aging: Psychologists Make a Significant Contribution. Addressing Mental Health Needs of Older Adults. Retrieved on February 15, 2016/Retrived/fromhttp://www.apa.org/pi/aging/resources/guides/ psychology-and-aging.aspx

PESHAWAR JOURNAL OF PSYCHOLOGY AND BEHAVIORAL SCIENCES, 2016,VOL.2,NO. 2, 249-261 
Arif Umaima and Ahmed Eatzaz (2010). Pension System Reforms for Pakistan: Current Situation and Future Prospects. Islamabad: Pakistan Institute of Development Economics. PIDE Monograph. P. 7

Cawthorne Alexandra (2008). Elderly poverty: The Challenge before Us. Centre for American Progress. Retrieved on February 20, 2016 retrieved fromhttps:/www.americanprogress.org/issues/poverty/report/2008 /07/30/4690/elderly-poverty-the-challenge-before-us/

Cassum A. Laila (2014). Elderly Depression in Pakistan: An Emerging Public Health Challenge. Karachi: International Journal of Innovative Research and development. Vol 3 Issue 5, p. p 698.

Cherchye. L, B. De Rock \& F. Vermeulem. (2008). Economic Well-Being and Poverty among the Elderly: An Analysis Based on a Collective Consumption Model. Discussion paper Series. Forschungsinstitutzur Zukunft der Arbeit Institute for the Study of Labor. IZA DP No. 3349.

Chohan A. Riaz. (2007). Social isolation in old age, responsibilities of family members, rights of senior citizens, A case study of Quetta district. P.hD thesis.

Daily Dawn. (2011, Oct, 4). Challenges for senior citizens.P.6 Retrieved on March 31, 2016 from http://www.dawn.com/news/663749/challenges-for-seniorcitizens

Dildar, Saeed and Sharjeela (2012). Exploratory Study of the Nature of Violence against Elderly in District Gujrat, Pakistan. Lahore: Academic Research International. Vol. 2, No. 3, May 2012

Muhammad, N., Jan M. A, Shah M, \& Ahmad Z. (2009). Old Age People: A Socio-Economic View of their Problems in Peshawar City. Pakistan Journal of life social sciences. 7(2): 126-130

PesicLjiljana (2007). Social and Health Problems of the Elderly. ActaMedica Medianae 46 (2): 45- 48.

Wazir A Muhammad (2013). Population Dynamics in Pakistan: Past, Present and Future. Islamabad: Sustainable Development Policy Institute (SDPI). P. 3.

Mansoor Hasan (2016). Pakistan lacks policy for its fast growing elderly population. Karachi: Daily Dawn Jan 27, 2016 Retrieved on Jan 27, 2016 Retrieved from http://www.dawn.com/news/1235585

PESHAWAR JOURNAL OF PSYCHOLOGY AND BEHAVIORAL SCIENCES,2016,VOL.2, NO. 2, 249-261 
National Coalition for the Elderly (2009). Homelessness among Elderly Persons. Washington: Retrieved on February 10, 2016 Retrieved form http://www.nationalhomeless.org

Sabzwari R. Saniya and Azhar Gohar (2010). Ageing in Pakistan-A New Challenge. Aging Int. Springer Science and Business Media. P. 3

Salahuddin K and A.A Jalbani (2006) Senior Citizens: A Case Study of Pakistan. Karachi: Journal of Independent Studies and Research (JISR) 4 (2): 26

M.T. Yasamy, T. Dua, M. Harper, S. Saxena (2013). Mental Health of Older Adults, Addressing A Growing Concern. World Health Organization, Department of Mental Health and Substance Abuse. P.3 